\title{
Marketing and Sales Processes
}

\section{The Marketing vs. Sales Debate}

Although marketing and sales are closely related to distribution, the topic of the previous chapter, these two activities have been separated here in order to give both disciplines, and how they have been pursued by the sample companies, the special attention they deserve. Despite the fact that sales are generally regarded as a subelement of marketing, in practice, many firms separate the two organizationally and treat them at equal levels. Additionally, in consumer-oriented companies, marketing occupies a special stature due to its brand-building role. In most businessto-business (B2B) companies, those selling to other companies, it is sales that take the lead. Among the 36 researched companies, only a few can be categorized as predominantly business-to-consumer (B2C), selling directly to consumers (Jura, Caran d'Ache, Ricola, Kuhn Rikon). On the topic of branding and marketing, most of the examples will feature these companies.

\section{B2C SMEs Engaging in Global Brand Building}

Practices among the B2C companies vary considerably depending on size. Companies with sales above CHF 300 million, such as Jura and Ricola, can engage more directly with consumers worldwide and mount truly global campaigns. On the other end of the spectrum are companies like Kuhn Rikon and Caran d'Ache, both of which engage in brand-building activities but also emphasize different tools. However, none of these companies compete solely on classical marketing brand building.

For Swiss SMEs, the concept of brand value was central to their competing. Consumer products, often not sufficiently protected by intellectual capital in the form of patents, faced imitators at every step, particularly if they were commercially successful. 
Developing and nurturing a global brand can protect the company from imitation by low-cost competition; it also helps differentiate the firm and justify the higher price inherent with products produced mainly by the high-cost Swiss base. Such a brand defense strategy was employed globally by Jura marketing its espresso machines.

Jura espresso machines were subject to imitation and copying, and Jura believed that a strong brand was much more difficult to copy. Around its product line focused on the best coffee, most attractive design and ease of use, the company built what it called "The House of Jura", combining a strong brand, controlled distribution and outstanding service on its machines. Since 2006, Jura has collaborated with the Swiss tennis star Roger Federer as the main spokesperson for the brand. Jura saw a strong brand image as security for its customers that the product would live up to expectations. Jura's worldwide identity helped to strengthen the brand wherever customers travelled, be it for business or for leisure activities. The global identity was not created for the sake of standardization but rather to signal consistent quality and to facilitate customer perception of the Jura brand. ${ }^{1}$

Ricola also emphasized and articulated its brand values. Similar to Jura, where its spokesperson Roger Federer allowed for a connection to Swiss quality and Switzerland, Ricola included Swissness as part of its own brand value.

Ricola's brand values were focused on the consumer. The company summarized them as functionality (good for your throat), enjoyment (in terms of good taste, not as a medication) and Swissness for its heritage. These three values were essential for the Ricola brand expression and if any given product did not contain those three, it could not be a Ricola branded product.

Organizationally, Ricola had moved over time from having its distribution partners play a major role in supporting the brand locally, to centralizing this task, a process that had already progressed very far at Jura. The recent emergence of social media also strengthened the drive toward centralization while making this tool a critical element in promoting the Ricola brand.

\begin{abstract}
Maintaining the core values at Ricola was the responsibility of brand management. Originally, the company had relied more on its distribution partners in the countries to position the brand locally. Over the past years, brand management became an increasingly centralized task to avoid different interpretations of the Ricola brand by different partners, and to make more global brand marketing campaigns possible. A special role was played by social media, with Ricola market research engaging consumers on a daily basis to take the market pulse. In fact, until 2005, the company had little direct contact with consumers. The arrival of social media changed all that. The Ricola brand values were very much focused on the consumer and social media would signal to the company if changes were taking shape. Ricola would then adapt its product assortment. ${ }^{2}$
\end{abstract}

\footnotetext{
${ }^{1}$ Adapted from Jura company profile.

${ }^{2}$ Adapted from Ricola company profile.
} 
The impact of social networks and the Internet also caused Caran d'Ache to change its marketing and brand-building strategy. With a long tradition of marketing its products globally through independent distributors, the emergence of online sales as an important tool offered a new, more central, role to the company's marketing operation. Another important element was the development of concept stores, and the first one was opened in Geneva, where company employees could have direct customer contacts and provide feedback to the central marketing staff.

Caran d'Ache invested about 10 percent of sales in marketing activities. The company believed that 80 percent of the population would search for products and product information online and then go to a store. The company opened its own e-shop on the internet.

The most recent development was building concept stores. The company came to the conclusion that its own retail store was needed in Geneva, as much for marketing as to understand the retail environment by engaging directly with customers. Feedback meetings were held on a monthly basis between retail and marketing staffs. The Geneva store was run by Caran d'Ache employees. Other concept stores were franchised with partners in Berlin and Tokyo. ${ }^{3}$

With a traditional distributor network in place, direct feedback from customers was difficult to obtain. Smaller Swiss companies, in particular, were looking for such direct contact. Given that Switzerland is in itself a travel destination for global tourists, such opportunities exist in key tourist locations such as Lucerne and Geneva.

Kuhn Rikon, producer of pans and cooking utensils, and one of the smaller players among the researched SMEs, focused on B2C marketing and tried to compensate for size with marketing innovations. The company was recognized by the Swiss Marketing Association for its success in brand marketing.

\begin{abstract}
Kuhn Rikon aimed at "selling stories, not products." Lack of brand power on an international basis had to be compensated by being quicker on innovations. On the distribution side Kuhn Rikon practiced multi-channel marketing. The traditional retail channels such as Migros in Switzerland or William Sonoma in the US, were enhanced through direct sales on TV shopping channels. These TV programs were particularly strong in the UK, Germany and the US, and allowed for demonstrating, and telling about, the products. Online shopping, such as through Amazon and Alibaba Tmall, also became more important, where independent distributors stocking Kuhn Rikon products manned their own "store." Kuhn Rikon did not sell directly on Alibaba. ${ }^{4}$
\end{abstract}

The identification of products as Made in Switzerland has been made more restrictive under recent regulations. ${ }^{5}$ These changes had considerable impact on Kuhn Rikon, where parts of its product line continued to be produced in Switzerland

\footnotetext{
${ }^{3}$ Adapted from Caran d'Ache company profiles.

${ }^{4}$ Adapted from Kuhn Rikon company profile.

${ }^{5}$ Swiss confederation SME portal for small- and medium-sized enterprises. www.kmu.admin.ch. Accessed February 2, 2020.
} 
and others were sourced from external producers, largely from Asia. The company therefore had to adapt its brand marketing globally to fit the new regulations. To get around it, the label Swiss Designed was introduced for a segment of its product line, a solution also adopted by other SMEs.

The debate about what constituted Swiss Made was of considerable importance to Kuhn Rikon. After out sourced products from outside of Switzerland could no longer be advertised as Swiss Made, the company, after several false starts, moved towards a differentiated labeling of its product line. The cookware made entirely in its Rikon factory continued to be labeled as Swiss Made and the use of the Swiss flag was authorized. The company's kitchen gadget and utensil line could no longer be sold under that label, even if the items were brought to Switzerland and packaged there. Like other firms, Kuhn Rikon changed to label its products as Swiss Designed, but had to forego the use of the Swiss flag on its packaging. ${ }^{6}$

\section{Professionalizing the Marketing Process}

The migration from selling to marketing and branding was a slow process for most SMEs. Starting out with a technical innovation and dependent on personal selling by the company founder, marketing departments, considered standard today, were slow in coming. Clearly, the B2C companies took the lead. The trigger was often the need to break through the distributor-monopolized contact with local consumers and the sheer difficulty for the Swiss exporter to gain significant customer insights to guide the operations. Felco is a case in point. Focused more on B2B users in the agricultural sector, the company also has had a sizeable following among home users, thus making direct consumer knowledge important.

For the first 50 years of its history, there was no formal marketing function or department at Felco. The major customer and trade facing activities were selling through distributors, and the building of a related network of independent distributors in many countries. Starting in 1989, in some key areas, Felco set up its own sales subsidiaries, such as in Belgium for the Benelux region, France, Australia, Germany, Canada (2011) and the US (2012). In 2009, Felco created a sales subsidiary in South Africa with 40 percent ownership from local partners. The decision to create a formal marketing department was taken by CEO Laurent Perrin around 2008 when the company realized it needed to better understand its customers. Focus groups and research determined that while the brand was well known and its products were highly appreciated, the company was not viewed as innovative nor was it perceived as listening enough to its customers. When the company realized how many vineyard workers developed muscular problems, the idea of a cordless battery-operated pruner emerged. ${ }^{7}$

\footnotetext{
${ }^{6}$ Adapted from Kuhn Rikon company profile.

${ }^{7}$ Adapted from Felco company profile.
} 


\section{It's All in a Name}

Even the brand name itself can become part of the story a company can utilize to support its global brand image. Possibly, the most unusual story behind its brand name was represented by Caran $\mathbf{d}^{\prime}$ Ache. The early founders of the company explained the origin their brand name as follows.

\footnotetext{
The company adopted the pen name used by the widely known Russian-born French illustrator Emmanuel Poiré (1858-1909), who drew under the pseudonym of Caran d'Ache, as the company name and as of 1924 branded all of its products under this name. The appropriated name was related to the Russian term karandash for pencil with had its origin in the Turkish language kara tash for black stone, the origin of graphite. ${ }^{8}$
}

Some of the SMEs researched struggled with the adaption of company names to foreign tongues and, in the interest of simplicity and catchiness, changed their name or that of their brand. Plumettaz, the cabling equipment maker based in Aigle (VD), early in its history found that customers outside of its Swiss Romandie region mispronounced its name, eventually settling on Plumett as the brand name for its equipment.

Similarly, Lantal as a company name was established to be easier to remember internationally. And finally, there was Sefar, found that the name resulting from a merger of several companies, Seiden-Fabrikanten Réunion, or Silk Manufacturers Union, was too cumbersome and shortened it to Sefar. A similar shortening of the name was practiced by Emil Richterich \& Co. Laufen into Ricola. After all, the name is important!

\section{Marketing and Selling in a B2B Environment}

The majority of the researched SMEs operate in the field of B2B. Their customers are not the end users but other, usually technically trained individuals, who incorporate the SMEs' products into other technical solutions. These SMEs are marketing components, parts, modules, or subsolutions that are often critical to the production process or the final products of their customers. Marketing is therefore driven by technical sales, which can take various forms. Much of the success of these firms depends on the effectiveness and professionalism of the technical sales effort.

Selective information indicates that many of the early founders also had a strong bent for salesmanship. To go out and face prospective customers, risk being turned down and literally go door to door, were skills some of the early founders possessed. They must have been good communicators because this required them to explain and justify technical improvements to a skeptical audience, often one that was not trained in the of the founder's technical skills. Examples such as LNS founding partner

\footnotetext{
${ }^{8}$ Adapted from Caran d'Ache company profile.
} 
Scemama, Plaston founder Frei, and Bachem founder Grogg are typical for founder personalities with that skill.

Even today, company owners or CEOs often play the role of CMO by spending a considerable amount of time with customers, visiting them and walking through their plants. Komax founder Koch spent considerable time in the plants of his customers, suggesting different ways to improve their operations and gathering new ideas for himself. Attending international trade fairs was another preferred way to meet existing customers, recruit new ones, and exchange information.

\title{
Application-Driven Sales
}

When application-specific selling is critical, SMEs tend to decentralize their sales effort to be closer to the customer. This is particularly true when the engineering task of the product, system, or module has already been completed and the next step is to show customers how to apply this within their own operations. The extent of decentralization varies from company to company.

Sefar employed a large sales force across the globe. The sales force also played a role in application development.

\begin{abstract}
Sefar employed hundreds of technically savvy salespersons. The 26 national subsidiaries also had the task of knowing which industries produced what. It was the task of the sales force to understand how customers handled the filtration processes and to see how Sefar could help. Thus, they understood customer needs and also approached customers on their own. There were lists of strategic industries for every country, which the national subsidiaries had to target. As a result, most of Sefar AG's products and services have been developed in collaboration with customers or were developed almost exclusively in response to specific customer problems. ${ }^{9}$
\end{abstract}

At Oetiker, the manufacturer of clamps and systems used by tier suppliers to the automotive OEMs employed a globally dispersed sales force with deep application know-how in customer operations, who service the thousands of company customers throughout the world.

\begin{abstract}
At Oetiker, sales operations were in the hands of a number of application managers, not product managers, who were globally distributed and held regional responsibility. The application managers' task was to spot opportunities and in some cases anticipate as well. The starting point was always the client's needs. Some of these application managers were based at production locations, with the majority operating from simple sales offices only. This distributed sales and customer service operation allowed the company to interface with customers in their own culture and language which Oetiker considered a competitive advantage as many products were in need of customization. ${ }^{10}$
\end{abstract}

\footnotetext{
${ }^{9}$ Adapted from Sefar company profile.

${ }^{10}$ Adapted from Oetiker company profile.
} 
At LEM, where sales were partially made from a catalog of components, there remained a need to be close to the specifiers at the individual customers in many different application settings. Maintaining a distributed sales force enabled the company to adapt easily to the specific national and cultural sales settings.

The need to be close to customers led to the establishment of more than 20 sales offices across the world. Its global customer base demanded seamless service worldwide. LEM also had to accommodate different selling cultures. In the US Rust Belt, or Midwest, the sales approach was traditional, whereas in Silicon Valley there was a different kind of engineering thinking. This meant LEM had to use two different sales groups to accommodate different sales dynamics by market segments and geographic region. ${ }^{11}$

\title{
Employing Key Account Systems
}

In cases of large customers which operated in a number of geographic territories, larger companies in the sample also employed Key Account Management (KAM) systems for coordination purposes. Typically, these KAM managers were located at the head office from where they coordinated application or sales teams which were deployed regionally. Komax, manufacturer of cabling systems, was a case in point.

\begin{abstract}
Komax sales reflected the worldwide distribution of wire harness producers, particularly those devoted to the automotive industry. All sales and service organizations were companyowned firms, engaged both in sales and service. Sales to global key accounts were coordinated from the head office in Switzerland. Customers were offered a single point of contact for their business with Komax. Only about 2 percent of Komax Group sales were to Swiss customers. Europe accounted for the largest share with about 50 percent, followed by Asia/ Pacific with 20 percent, Americas with 15 percent and Africa with 10 percent. ${ }^{12}$
\end{abstract}

In the case of Lantal, location of sales offices and KAM were combined. The company operated sales offices in Seattle to leverage proximity to Boeing, as well as a sales office in Toulouse to serve Airbus.

When an engineering solution had to be finalized upon customer order, requiring considerable design engineering for each product up front, the sales effort was centralized. This was the case for engineering intensive firms, such as Burckhardt Compression.

At Burckhardt Compression, new machine sales, although global in nature, were from the Swiss base where most of the technical expertise was concentrated. The sales process was highly technical and required considerable know-how regarding the various processes and required installations. The center of competence for sale was thus maintained in Switzerland, with a few sales experts stationed in the US and China. The footprint and organization for the service business was different and more decentralized. ${ }^{13}$

\footnotetext{
${ }^{11}$ Adapted from LEM company profile.

${ }^{12}$ Adapted from Komax company profile.

${ }^{13}$ Adapted from Burckhardt Compression company profile.
} 
In contrast, Sécheron decentralized its sales activities by placing considerable resources into local markets. The company credits its success in Asia with this redeployment.

EAO, manufacturer of push-button systems, was long geared toward international sales, covering some 50 countries or regions. It adopted the model of direct sales combined with a dispersed sales force.

\begin{abstract}
The EAO business model relied on direct sales. Eleven sales companies across the world assisted in this model, resellers were excluded. A sales force of about 50 people, spread out and dispersed geographically, tended to the customers. EAO was of the view that sales contacts needed to be held by people rooted in local customs. The globally spread sales force kept in touch with sales call-ins every three months and an annual two-day sales meeting. Direct links among sales teams and sales companies were encouraged to avoid that connections had to go through the center in Olten. Global segment managers were in place, important for segments such as railroad that was global in nature. Data needed for the sales force, such as the company's CRM system, were cloud-based and could be accessed globally by all members of the sales teams. They were asked to register all complaints in the system, as well as any opportunities spotted. ${ }^{14}$
\end{abstract}

How complex a global sales force and its management can become is best illustrated by u-blox. The company marketed its positioning modules and components only through OEMs. The company did not market GPS products as naked products, nor did it market to end users.

\begin{abstract}
At u-blox, sales to OEM customers were in the hands of three crews with regional concentration on Europe, North America and Asia/Pacific. These teams could count on the support of 13 sales offices and about 50 distributors in key countries. The opening of international sales offices started early, with u-blox opening US and Asia offices in 2001. In 2018, u-blox geographic sales were about evenly divided between Asia/Pacific (35 percent), Europe/EMEA with 32 percent and Americas with 32 percent. Sales to Switzerland, the head office location of the company, accounted for less than one percent. Coordination of the sales effort was largely the responsibility of the newly created position of CMO. Sales teams and their members traveled extensively. The sales teams worked on requests for products placed by OEMs. u-blox sold components and chips, with the former accounting for the majority of sales. ${ }^{15}$
\end{abstract}

\title{
Global Sales Practices in the Medical Cluster
}

For SMEs that are part of a medical cluster, it is important to alert readers to the special practices these firms followed. Geistlich und Medartis demonstrated similarities in their sales approaches by adopting a special form of focus on specific customer franchises or professional groups. The need to get close to these professional groups, dental and orthopedic surgeons, required the fielding of a highly specialized sales force that could access the practicing surgeons directly.

\footnotetext{
${ }^{14}$ Adapted from EAO company profile.

${ }^{15}$ Adapted from u-blox company profile.
} 
In line with the company's orientation, a specific business model was required. Geistlich Pharma customers were dental surgeons located all over the world. In order to reach dental surgeons, the company put its emphasis on direct sales and meeting customers at conferences, actually conducting its business without a formal sales force. Surgical procedures could be demonstrated during those conferences. To support the educational effort that went into communicating the use of biomaterials for bone enhancement, the Osteology Foundation was created in 2003. A second foundation, the Osteo Science Foundation, was established in 2013 and also supported by Geistlich. The company efforts did not only help the sale of its products, but contributed greatly to the increased use of regenerative bone materials globally. Geistlich dominated this niche in whose creation the company had played a major role in the first place. ${ }^{16}$

In order to reach its chosen customer franchise of orthopedic trauma surgeons, Medartis preferred a direct sales force for most of its customer contacts. For a company with about 550 employees globally, some 200 were in its field sales force, employed full time by Medartis and based on its international subsidiaries. The deployment of such a large field sales force, coupled with an industry and company experience averaging 11 years, gave Medartis the needed control influence over the sales process, surgeon education, and surgeon training.

International expansion at Medartis began in 2002 with the opening of sales offices in Germany, Austria and France. Other sales subsidiaries followed: in the UK (2003), the US (2004), in Mexico and Poland (2008), and in Australia and Spain (2010). The most recent sales subsidiaries were formed in 2018 through the acquisition of a local distributor in Brazil and a new operation in Japan. In addition to its 11 sales subsidiaries employing about half of its staff, Medartis products were also sold in 40 countries through 35 distribution partners, collectively accounting for about 15 percent of sales. ${ }^{17}$

SMEs in the medical cluster that developed cutting-edge technology would not be able to achieve the needed sales volume to monetize such development without a large field sales force of highly skilled professionals capable of gaining the confidence and trust of the surgeons. For these firms, the global sales force accounts for as much as one-third of their total head count.

\section{The Importance of Lead Customers}

A review of the sales histories of many of the SMEs points to the important role played by a lead customer. A lead customer is not merely a customer who became an early buyer but is also one that resonated in the industry and literally put the company on the map. Some of our SMEs showed considerable skill in grabbing such opportunities and often outdid much larger competitors who were not willing to go the extra mile to satisfy a special request. The examples given below show that a

\footnotetext{
${ }^{16}$ Adapted from Geistlich company profile.

${ }^{17}$ Adapted from Medartis company profile.
} 
lead customer can emerge at any time during the development of an SME, be it at the beginning, in mid-career, or during times of distress.

Wyon, producer of specialty batteries, was still in the process of troubleshooting its prototypes when an Australian company arrived at its doors to eventually become not only a lead customer but a launch customer.

In 2001, the Wyon founders had the first prototypes, still not optimal and with some faults, when a representative of a large Australian company and worldwide leader for cochlear implants, appeared on the stage. The company had been looking in vain for a supplier to produce rechargeable batteries for their purposes. At that time, they were still collaborating with Phonak, a leading Swiss hearing aid producer, who recommended to approach Wyon. The Australians came to Appenzell when Wyon was still operating out of a garage. Wyon convinced them that they were the right partner and commenced the development of a first prototype. CEO Philipp Wyser explained the specific market niche of Wyon as follows:

If you go to a battery manufacturer and say that you want a special shape, then the first question is: 'In what quantity?' The Australians only needed 30-40,000 batteries a year, and then the battery manufacturer typically said: 'Here you have my catalogue, choose a standard battery. If we're talking about a million a day, we'll make a special one for you.' They just don't do that, it's not worth it for them to change their equipment for 30,000 units. In principle, this is also part of the market niche we have worked on, that we are somewhere where others don't want to go (Wyser, CEO).

Wyon targeted the implant hearing sector because the normal hearing aid sector was simply not yet 'ready' for rechargeable batteries, as audiologists partly earned their money selling replacement batteries. In 2005, Wyon moved out of the garage, rented the first commercial premises and started with serial production for their first customer. ${ }^{18}$

By going the extra mile, Wyon was able to compete in a niche that the large battery producers were unwilling to invest in. To be able to grab such an opportunity and become a reliable supplier is a typical game where many Swiss SMEs excel.

FISBA chose to take the route of an exclusive OEM arrangement, one that lasted from 1965 to 2016. The OEM arrangement, while providing a steady customer over decades, came with restrictions and exclusivity and was eventually terminated. Having matured, FISBA could develop beyond its lead customer and find new business.

In 1965, FISBA initiated a cooperation with KARL STORZ, a large German endoscope producer, for which it exclusively produced micro-optics. For a modern endoscope to provide brilliant images of hidden body cavities the key parameters were light intensity, depth of focus, magnification, contrast, and resolution. FISBA focused on design, its traditional strength. FISBA tried to develop customized designs and then to become the manufacturer of the product. As a result of this cooperation, FISBA's business grew at a steady pace. Three times FISBA expanded into new production facilities, serving as "extended work bench" and strategic supplier in micro-optics for KARL STORZ until $2016 .{ }^{19}$

\footnotetext{
${ }^{18}$ Adapted from Wyon company profile.

${ }^{19}$ Adapted from FISBA company profile.
} 
Plaston, expert in producing plastic components through injection molding processes, had been operating for a good 20 years, producing components for both industrial and consumer applications, when the company was contacted by Hilti, a large global company in the power tool market. Hilti, located in nearby Liechtenstein, had decided to close its in-house plastics laboratory and offered Plaston its equipment for sale. The companies were located only about $30 \mathrm{~min}$ from each other by car in the Rhine River Valley, on the Eastern border of Switzerland.

Hilti had just made the decision to close its in-house plastics laboratory and had offered its surplus equipment to Plaston. During a visit to the Hilti warehouse, Hans Frei, the Plaston founder, discovered piles of red metal cases used to package Hilti power tools. "These cases could also be made out of plastic" said Frei. Hilti replied, "We already have enough problems with our power tools, we don't want to add more problems with the cases." Frei did not take no for an answer and for the next two years, he, his son Roland and a small, dedicated team worked hard to create a series of prototypes with the hope of impressing the people at Hilti. Maybe it was the constant pressure, but Hilti finally agreed that Plaston could produce cases for one of their power tool models, at Plaston's own risk. Eventually, Hilti's decision to sell their complete line of products in specially designed Hilti red cases was both a confirmation and a challenge for Plaston, because the scope of this project went beyond everything Plaston had ever experienced before. Three more product lines for Hilti would follow in 1980, 1990 and 2005. By 2010, 40 mio cases were sold and the fifth generation of cases was in development. ${ }^{20}$

The persistence of Plaston founders and family paid off handsomely, providing the boost the company needed to launch an extended period of growth. Eventually, many other companies turned to Plaston for similar products, but Hilti remained their largest customer. The red plastic cases for Hilti power tools can be seen on building sites all over the world.

Even well run, growing and profitable companies can profit from the emergence of a single lead customer as demonstrated by Thermoplan. Started in 1974 by Domenic Steiner, the company had grown from the business of installing institutional kitchens to producing cold cream and milk foam whipping equipment for use in coffee bars. After some business associates had suggested that Thermoplan try to combine its equipment and build it into a fully automatic espresso machine, the company brought its prototype to a fair in Basel.

Official market introduction took place at the Basel fair in 1997 where Thermoplan as a newcomer for automatic professional coffee machines, caused quite a stir. Adrian Steiner, later to become CEO of Thermoplan, remembered the situation at the Basel Fair exhibition booth.

The Thermoplan team manning the booth was visited during the fair by three guys from Seattle: Peter, Paul, and Larry. They were intrigued by the Thermoplan solution and informed the team that they were from a coffee chain named Starbucks, a company that was not known to the Thermoplan team at that time! The Starbucks team let the Thermoplan

${ }^{20}$ Adapted from Plaston company profile. 
team know that they were looking at some 14 different machine suppliers and required a machine that could deliver both speed and consistency (Steiner, CEO).

After an evaluation of several machine suppliers, Starbucks included the Thermoplan as one of three suppliers in its six months' testing phase and allocated to Thermoplan a site in Vancouver, Canada. As Steiner recalled: "This was not the typical Rössli in Switzerland." Over the six months' pilot testing phase, Thermoplan managed to constantly adjust and improve its machine, impressing Starbucks with both flexibility and performance. This was the time when coffee tastes in the US began to change and the preference for caffe latte was just about to take off. In 2000, Thermoplan signed a long-term, exclusive, global supply contract with Starbucks for all its coffee shops. At the time of this negotiation, Thermoplan had about 35 employees. For Thermoplan, just two things mattered in this contract, the rest was viewed as legal jargon. First, the purchasing terms were in CHF and not in USD, eliminating any currency risk. Second, payments were to be made within ten days after invoicing. This was critical for a company that was sourcing most components from small local suppliers and could thus provide financing to them. ${ }^{21}$

The willingness to take the plunge with a lead customer, such as Starbucks about to roll out its stores worldwide, when the company was still very small, proved to be decisive to allow Thermoplan to grow its business to CHF 300 million in less than 20 years.

Selectron, a producer of in-train electronics, was a last example: When new management took over in 2000, the company had been in decline for its last 10 years of operation and was slated to be liquidated. The newly appointed management was actually able to engineer a complete turnaround from industrial electronics to in-train electronics by capitalizing on its relationship to the SBB as its initial lead customer, and later by riding the coattails of Stadler Rail, a newcomer who grew to a dominant player in the suburban train segment.

Selectron's competitiveness as a supplier to the Swiss Railway was based upon its willingness to varnish the electronic controls and select ruggedized components to meet the stringent requirements for train operations and the fact that in the past, to compete in the machine tool automation segment, the company had consistently reduced the size of its controllers, which helped to fit items into the tight spaces of railway cars. If the PLCs were not varnished, the reliability of the equipment was not assured. Condensation caused by temperature differences, as well as dust accumulated from steady use, could result in short circuits in the system. Major automation suppliers were not interested in taking this extra step and would force the railway operator to use unwieldy protection boxes instead. ${ }^{22}$

The successful fulfillment of the SBB's contract for retrofitting refurbished rail cars with in-train automation control systems led to further developments that helped Selectron to latch on to OEM train builders for new equipment. In Europe, half of the new train market was dominated by three large international players who all had their own in-house train automation departments and were not interested in an external niche supplier. The other half of the market, supplied by smaller, regional train builders, was dependent on sourcing in-train electronic control systems and at

\footnotetext{
${ }^{21}$ Adapted from Thermoplan company profile.

${ }^{22}$ Adapted from Selectron company profile.
} 
the same time hesitant to do so from the larger integrated companies who were also their main competitors. By supplying Stadler Rail, the emerging leader among this second segment, Selectron was pulled into the market as a new equipment supplier. What was once a small business of just about CHF 2.5 million grew into a sizeable international business of CHF 70 million. Stadler remained the largest customer, albeit Selectron could gain other customers as well. A company slated for liquidation was rejuvenated through its close relationship with its lead customer Stadler.

\section{Review}

B2C SMEs generally followed branding practices that were widely followed in consumer marketing. SMEs in this segment, however, were challenged to operate with relatively smaller budgets, thus requiring innovative branding practices that conserved their limited budgets (Caran d'Ache, Felco). Jura and Ricola, larger and thus able to invest greater resources into brand building, could aim for globally oriented campaigns, though both companies also chose tactics that respected their limited resources.

The B2B set of SMEs emphasized selling through a professional and technically trained sales force that could also solve customer problems (Medartis, Geistlich). This more consultative style of sales representation called for a globally dispersed sales force (LNS) with heavy reliance on key account selling (Komax, Lantal, u-blox). In order to facilitate new product introductions, lead customers proved helpful to open doors elsewhere once they were fully satisfied (Wyon). The lead market concept was particularly important for smaller companies, since it conserved on the expensive selling resource by focusing it on one, or a few, target customers prior to expanding market coverage to a greater number of prospective clients (Thermoplan, Selectron). In some instances, these relationships became quasiinstitutionalized and continue to last for long periods (Plaston, FISBA), serving the SME as anchor points for further market expansion.

Open Access This chapter is licensed under the terms of the Creative Commons Attribution 4.0 International License (http://creativecommons.org/licenses/by/4.0/), which permits use, sharing, adaptation, distribution and reproduction in any medium or format, as long as you give appropriate credit to the original author(s) and the source, provide a link to the Creative Commons license and indicate if changes were made.

The images or other third party material in this chapter are included in the chapter's Creative Commons license, unless indicated otherwise in a credit line to the material. If material is not included in the chapter's Creative Commons license and your intended use is not permitted by statutory regulation or exceeds the permitted use, you will need to obtain permission directly from the copyright holder.

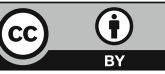

